\title{
Evolution of host-selection behaviour in insect herbivores: genetic variation and covariation in host acceptance within and between populations of Choristoneura rosaceana (Family: Tortricidae), the obliquebanded leadfoller
}

\author{
Y. CARRIERE* \& B. D. ROITBERG \\ Center for Pest Management and Behavioural Ecology Research Group, Department of Biological Sciences, Simon \\ Fraser University, Burnaby, BC, Canada V5A 156
}

\begin{abstract}
Populations of insect herbivores exploiting habitats that differ in host species composition may experience selection for divergent host-selection behaviour. To assess potential genetic constraints on the evolution of host-selection behaviour in such populations, we estimated genetic variation and covariation in larval acceptance of different host species within and between populations of the obliquebanded leafroller, Choristoneura rosaceana. Host-acceptance behaviour was analysed using the threshold model of quantitative genetics. According to this model, there is a continuously distributed variable describing the motivational/physiological state of individuals in the population, and a threshold of acceptance representing the acceptability of a host species. Individuals in which this variable exceeds the threshold accept the host while individuals below the threshold reject it. Parent-offspring regressions, a selection experiment, and comparisons of full-sibs in three pairs of populations revealed significant additive genetic variation in host acceptance. Genetic correlations between the responses to different hosts were either positive or not significantly different from zero, suggesting that local change in host acceptance will not favour behavioural specialization in populations of $C$. rosaceana. The pattern of the reaction norms for host response in the pairs of populations confirmed that divergence in host-selection behaviour does not involve behavioural specialization in the obliquebanded leafroller.
\end{abstract}

Keywords: Choristoneura rosaceana, genetic correlation, heritability, host-selection behaviour, quantitative genetics, threshold trait.

\section{Introduction}

The frequency and suitability of host plant species encountered by insect herbivores can vary in space and time because of heterogeneity in the environment, disturbance, colonization and intra- or interspecific interactions (Thompson, 1985; Singer, 1986). Such variability could favour change in host-selection behaviour, and result in genetically-based divergence in diet among populations of plant-feeding insects (Otte \& Joern, 1977; Jaenike, 1978; Courtney, 1982; Futuyma, 1983; Rausher, 1984; Ward, 1987; Jaenike

${ }^{*}$ Correspondence: Department of Biology, McGill University, 1205 Dr Penfield Avenue, Montreal, Quebec, Canada H3A 1B1.
\& Holt, 1991). Indeed, many studies have reported evidence of such divergence among populations of insects in response to host plants (Table 1).

The potential of a population to undergo selective change in host-selection behaviour is determined by four factors: (i) the amount of phenotypic variation in host-selection behaviour, (ii) the genetic basis of such variation, (iii) the relationship between host-selection behaviour and fitness (Singer et al., 1989; Jaenike, 1990; Carrière \& Roitberg, unpublished observations), and (iv) migration that must be low enough to allow genetic divergence of the norm of reaction for host response (Futuyma \& Peterson, 1985; Bossart \& Scriber, 1995; Carrière \& Roitberg, unpublished observations). Genetic correlations between responses 
Table 1 Among-population comparisons suggesting genetically based variation in host-selection behaviour in plant-feeding insects

\begin{tabular}{lll}
\hline Order & \multicolumn{1}{c}{ Character } & \multicolumn{1}{c}{ Reference } \\
\hline Coleoptera & Feeding preference & Harrison(1987); Rowell-Rahier (1984) \\
& Oviposition preference & Wasserman (1986) \\
Diptera & Oviposition preference & Jaenike \& Grimaldi (1983); Prokopy et al. (1988); Tavormina (1982) \\
Lepidoptera & Larval host-selection & Futuyma et al. (1984); this study \\
& Oviposition preference & Bossart \& Scriber (1995); Phillips \& Barnes (1975) Schneider \& \\
& & Roush (1986); Thomas et al. (1987); Thompson (1993); Singer et al. \\
& & $(1992) ;$ Singer \& Parmesan (1993) \\
\hline
\end{tabular}

to different hosts could influence the evolution of diet (Arnold, 1981; Singer et al., 1992). For example, a positive genetic correlation between acceptance of a highly suitable host and of a toxic host could contribute to maintaining both hosts in the insect diet for an extended period if the toxic host is rare, or could lead to rapid avoidance of both hosts if the unsuitable host is abundant (Levins \& MacArthur, 1969; Futuyma, 1983; Fox \& Lalonde, 1993). Since genetic correlations between the responses to different hosts have rarely been estimated (Wasserman, 1986; Courtney \& Hard, 1990; Thompson, 1993), it is difficult to assess their importance in constraining diet breadth. The goal of this study was to estimate the heritabilities and genetic correlations of responses to different hosts in a species of plant-feeding insect, and to see whether these genetic parameters could be used to understand evolutionary change in its host-selection behaviour.

Local abundance of a single host species may result in diet specialization (Tavormina, 1982; Futuyma, 1983; Ward, 1987). Insect populations exploiting agricultural crops are subdivided among large patches of single hosts. When gene flow is low among patches, evolution of host-selection behaviour may occur independently in the populations exploiting different patches (Via, 1990). In this context, genetic correlations between acceptance of a host grown in a monoculture and acceptance of hosts that are absent in the monoculture may favour evolutionary change in diet breadth. Negative correlation between acceptance of hosts may result in behavioural specialization following the evolution of increased host acceptance in a monoculture, since migrants from the monoculture would then have reduced acceptance of other hosts. Positive or null correlations, however, could favour polyphagy, since increased acceptance of the host grown in the monoculture would result in increased acceptance of other hosts, or leave the response to these hosts unchanged.
In British Columbia, Canada, the obliquebanded leafroller, Choristoneura rosaceana (Harris), is a generalist herbivore that can exploit diverse agricultural crops and forests (Carrière, 1992a,b; Carrière \& Roitberg, 1994). Host selection is conducted by females that can fly and lay egg batches on the surface of host leaves, or by newly hatched larvae that can disperse on silk threads and sample many host species before settling. In Lepidoptera, larval dispersal results mainly in intrahabitat movements (Roff, 1990a; Thompson \& Pellmyr, 1991), and the same appears to be true for the obliquebanded leafroller (Gillespie, 1982; Carrière, 1992c). Therefore, even if $C$. rosacea$n a$ females determine to some extent the environment of their offspring, the behaviours of the larvae are likely to play an important role in host selection.

A previous study of the obliquebanded leafroller demonstrated that newly hatched larvae strongly discriminate among different host species, and suggested significant variation among larval genotypes in hostselection behaviour (Carrière, 1992c). The present study addresses the following three specific questions. (i) Is variation in larval host-acceptance genetically based in $C$. rosaceana? (ii) What is the pattern of the genetic correlations between responses to different hosts? (iii) Is local evolutionary change in host-selection behaviour favouring diet specialization or generalization in this species?

\section{Materials and methods}

\section{Bioassay to measure larval host-acceptance}

Host acceptance (sensu Singer, 1986) is measured by monitoring the response of an insect encountering a single host. Since acceptance estimates the response of an insect to a specific host (=environment), and $C$. rosaceana larvae contact plants sequentially in their natural host-search behaviour, host acceptance data 
are perfectly suited to calculating heritability of, and genetic correlations between, responses to different host species.

The following sequential protocol was employed to measure host acceptance (Carrière, 1992c): (i) 10 larvae were transferred to the leaf surface of each branch of the host(s); (ii) the branches were placed under perforated plastic containers (diam. $27.5 \mathrm{~cm}$, height $30.5 \mathrm{~cm}$ ) lined up in front of fans; (iii) the larvae were allowed to settle for $2 \mathrm{~min}$; (iv) the fans were started; and finally (v) the numbers of larvae remaining on the branches were counted after $60 \mathrm{~min}$. Care was taken such that the plants did not contact the containers and that no larvae fell off the plants before the fans were started. Insects were defined as having 'accepted' or 'rejected' a host if they were respectively on or off that host after $60 \mathrm{~min}$.

This bioassay had already been used to conduct two experiments (Carrière, 1992c). First, full-sib families were each divided into five groups that were simultaneously placed on four host species and on a control (a plastic 'plant'). This showed that variation in host acceptance was the result of host-selection behaviour and not of a host-independent propensity to move, because the larvae preferred three of the four plant species over the control. Secondly, full-sib groups were each divided in two and acceptance of apple branches was measured simultaneously in the laboratory or in the field (field larvae were counted $8 \mathrm{~h}$ after being placed on a tree). Apple acceptance measured in the two environments was found to be significantly and positively correlated, demonstrating the relevance of our laboraory bioassay.

This bioassay was used to estimate the heritability of apple (Malus domestica) acceptance, and to compare host-selection behaviour between pairs of populations of $C$. rosaceana, or between lines that had been selected for increased or decreased acceptance of broad bean plants ( Vicia faba). The bioassay was modified slightly (see below) to conduct the selection experiment. The larvae used in the bioassays (conducted at $24 \pm 1^{\circ} \mathrm{C}$ ) were less than $2 \mathrm{~h}$ old, naive (i.e. they had not encountered any host), and starved. The first egg mass of females was placed, prior to hatching, at a temperature of $7.5 \pm 1^{\circ} \mathrm{C}$, a relative humidity near 100 per cent, and under a $16 \mathrm{~L}: 8 \mathrm{D}$ photoperiod. This procedure (not used in the parent-offspring experiment below) synchronized hatching with light onset and facilitated control of larval age in the bioassays. All insects were raised on an artificial pinto bean diet (modified from Shorey \& Hale, 1965), and unless otherwise stated, at a temperature of $25 \pm 1^{\circ} \mathrm{C}$ under a $16 \mathrm{~L}: 8 \mathrm{D}$ photoperiod.

\section{Heritability of apple acceptance}

The proportion of larvae accepting a host within a family is approximately normally distributed within $C$. rosaceana populations (Carrière, unpublished data), and therefore host acceptance was assumed to be a threshold character (Mackay \& Doyle, 1978; Falconer, 1981). In this model, acceptance (or rejection) of a plant species is assumed to be determined by the interaction of a normally distributed underlying variable and a threshold. The distribution of the underlying variable represents the variation among individuals in their motivational/physiological state. The position of the threshold represents the level of the motivational/ physiological state above which a specific host is accepted. In this study, the threshold is assumed to be identical for all plants of a given species, but to vary among host species of different acceptability (sensu Singer, 1986). The underlying trait is assumed to be inherited in a typical polygenic manner (Falconer, 1981).

A parent-offspring regression technique (Roff, 1986) was used to estimate the heritability of apple acceptance (Introduction; objective i). Moths from the fifth generation of a colony $(\sim 300$ individuals collected from an apple orchard initiated a colony subsequently maintained at $\sim 200$ breeding individuals) were arbitrarily paired to provide parental families (the $F_{1}$ ). Apple acceptance was estimated in each $F_{1}$ family, and 30 larvae from each family were raised to adulthood. The $F_{1}$ moths were mated assortatively with respect to host response and apple acceptance was then measured in the $F_{2}$. Ten replicates (i.e. 100 larvae) were used to estimate apple acceptance in a given family.

The calculations of heritability were based on the pooled results of the 10 replicates conducted for each $F_{1}$ or $F_{2}$ family. Heritability estimates derived using single parental values were corrected for assortative mating using the formula given by Falconer (1981, p. $164)$, where family values of the $F_{1}$ generation were used to estimate the correlation between parents (Roff, 1990b).

\section{Selection for increased or decreased acceptance of broad bean}

This experiment was undertaken to confirm whether host acceptance is heritable (Introduction; objective i), and to determine whether direct selection on acceptance of one host may result in correlated responses in acceptance of other hosts (Introduction; objective ii).

Bean-acceptance behaviour was estimated in the same manner as apple acceptance, except that (i) 
smaller containers (diam. $21.5 \mathrm{~cm}$, height $13.5 \mathrm{~cm}$ ) were used to facilitate recovery of larvae that had left the plant, and (ii) larvae remaining on the plants were counted after $30 \mathrm{~min}$ to increase the number of families that could be measured. Bean plants (between 20 and $30 \mathrm{~cm}$ ) were cut and trimmed to bare their third and fourth pairs of unfolded leaves, and inserted in florist vials before receiving the larvae. Sixty larvae per family (six replicates) were measured. Larvae found on the plant or crawling in the containers at the end of a bioassay were respectively designated as 'stayers' or 'leavers'. For each of the 16 families selected to provide parents in a given generation (see below), 20 'stayers' (for families with the highest bean acceptance) or 'leavers' (for families with the lowest bean acceptance) were raised.

Bean acceptance was initially estimated in 24 families of the fifth generation of a colony (sampling and rearing procedures as above). The 'stayers' from the eight families with the highest bean acceptance were crossed to produce a line with increased bean acceptance, and 'leavers' from the eight families with the lowest bean acceptance were crossed to produce a line with decreased bean acceptance. In two subsequent generations of selection, bean acceptance was initially measured in 13-24 families within each line. Individuals from the eight extreme families in each line were then retained for the crosses.

To investigate whether selection on bean acceptance resulted in correlated responses to other hosts, individuals from lines selected for three generations were simultaneously tested on bean plants, and on apple and wild rose branches (Rosa sp.). Three replicates (i.e. 30 larvae) were used to measure simultaneously acceptance of each host in a family. Potted bean plants bearing second to fourth unfolded leaf pairs were utilized in these tests.

Variation in host acceptance (arcsine square-root transformed) in the first two generations of selection was analysed using one-way ANOVA $s$ with Family nested within Line and considered as a random effect. Line was considered a fixed effect. Host acceptance (arcsine square-root transformed) in the third generation of selection was analysed using a two-way ANOVA where Host and Line were considered fixed effects and Family nested within Line a random effect. Familymean correlations were computed to estimate withinline genetic correlations in acceptance of host pairs (Via, 1991).

\section{Comparison between pairs of populations}

These experiments were conducted to estimate genetic correlations between responses to different hosts (see Introduction; objective ii), and to assess whether populations exploiting different habitats diverged in their host-selection behaviour (see Introduction; objective iii). For each pair of populations larval responses were estimated on two hosts, each host being locally abundant and/or uniquely present in the habitat exploited by one of the populations.

In the first comparison, larval responses to apple and cherry branches (Prunus sp.) were compared between two populations collected in an apple and a cherry orchard at Winfield, BC (hereafter, Apple and Cherry populations). The populations were separated by less than $1 \mathrm{~km}$, which is within the flight range of moths. No apple trees were grown in the cherry orchard but some were found in its proximity (within $400 \mathrm{~m}$ ). Similarly, few cherry trees were found around the apple orchard. Leafrollers had been present in the apple and cherry orchards for at least 10 and six generations, respectively.

In the second comparison, larval responses to apple and blueberry branches (Vaccinium corymbosum) were compared between a population collected from a blueberry field at Pitt Meadows, BC ('site 2' studied by Gillespie (1982)), and insects originating from an apple orchard at Oliver, BC (hereafter, Blueberry and Apple populations). Assuming that no population extinction had occurred since Gillespie's study, the Blueberry population had been present for at least 20 generations. The history of the Oliver population is unknown. The populations were separated by $400 \mathrm{~km}$ and the Cascades mountain range. No apple orchards were seen in the vicinity of the blueberry field (over at least $10 \mathrm{~km}$ ), nor was blueberry grown in the valley in which the apple orchard was located (over at least 100 $\mathrm{km})$.

The last comparison was between larvae from an apple orchard at Winfield, $\mathrm{BC}$, and a population collected in a mixed forest near Apex Mountain, BC, about $250 \mathrm{~km}$ away (hereafter, Apple and Mixed forest populations). Leafrollers had been present in the mixed forest and the apple orchard for at least four and 10 generations, respectively. Many hosts palatable to $C$. rosaceana were abundant in the forest, but larvae were only found on mockorange (Philadelphus lewisii) and red-osier dogwood (Cornus stolonifera). Apple and mockorange were chosen to compare larval responses between the populations. No apple trees were grown in the area surrounding the mixed forest (over at least 14 $\mathrm{km}$ ) and mockorange was not seen in the vicinity of the apple orchard in Winfield (that orchard was surrounded by other apple orchards).

To avoid possible non-Mendelian parental effects, host-selection behaviour was measured in the $F_{2}$ from field-collected insects. The $F_{1}$ of the Blueberry population was reared at $19^{\circ} \mathrm{C}$ for approximately 2 weeks to synchronize insect phenology in the Blueberry and 
Apple populations. Nine and seven mating pairs, respectively, provided eggs to establish the Blueberry and Mixed forest colonies, whereas over 95 mating pairs started the colonies from the orchards. Such a difference results from the low population densities in the blueberry field and mixed forest.

Host acceptance in a family was simultaneously measured on two hosts, using at least four replicates (40 larvae) per host. Plant material used in the bioassays was collected either at the sites where the populations had been sampled (Mockorange and Blueberry populations), or at the Agriculture Canada Summerland Research Station. McIntosh (apple) and Lambert (cherry) cultivars were used in the tests because they were dominant in the orchards where the populations had been collected. The branches of each host species were arbitrarily sampled from at least 20 plants, and were used only once in the bioassays. Freshly cut branches were employed, except for mockorange and blueberry branches that were kept in water (at $7.5^{\circ} \mathrm{C}, 16 \mathrm{~L}: 8 \mathrm{D}$ ) for a maximum of three and nine days, respectively, before being used.

The variation in host acceptance (arcsine squareroot transformed) in each pair of populations was analysed using two-way ANovas with Population and Host treated as random and fixed effects, respectively, and Family nested within Population as a random effect.

Family-mean correlations were computed to estimate within-population genetic correlations in acceptance of host pairs. These correlations reveal potential genetic constraints on the evolution of norms of reaction in host-selection behaviour (Via, 1991). To increase statistical power, a single correlation was calculated for the apple-cherry population-pair. Pooling was done on the assumption that the populations were sympatric, and because they did not differ statistically in their genetic correlations between the responses to the hosts (Sokal \& Rohlf, 1981, p. 589). The genetic correlations were estimated separately within the other populations.

\section{Results}

\section{Heritability of apple acceptance}

Apple-acceptance behaviour had a high heritability (Table 2). The estimates calculated using male or female parental values were similar to the estimate obtained using mid-parent values. This suggests that non-Mendelian parental effects did not influence larval acceptance in this experiment (Falconer, 1981; Carrière, 1994).
Table 2 Heritability of apple-acceptance behaviour in Choristoneura rosaceana

\begin{tabular}{|c|c|}
\hline Regression & $h^{2}(\mathrm{SE})$ \\
\hline On male parent & $0.76(0.31)^{*}$ \\
\hline On female parent & $0.82(0.26)^{* *}$ \\
\hline On mid-parent & $0.73(0.17)^{* *}$ \\
\hline
\end{tabular}

${ }^{*} P=0.0047,{ }^{* *} P<0.0003$, d.f. $=1,27$.

\section{Direct and correlated responses to selection}

Bean-acceptance behaviour differed significantly between the lines after just one generation of selection, and significant variation among the families in hostselection behaviour was detected in the first two generations of selection (Fig. 1, Table 3). This indicates significant additive genetic variance for bean-acceptance behaviour within the selected population.

After three generations of selection, the lines still had significantly different bean-acceptance behaviour, and significant among-family variation in host-selection behaviour was detected (Tables 4,5 ). The host species were not equally preferred by the larvae, but the difference in host acceptance between the lines was apparently maintained across the three host species (Table 5; Host $\times$ Line effect). This suggests that direct selection on broad bean acceptance had indirect effects on the response to the apple or rose hosts, and therefore that positive genetic correlations in response to the bean-apple and bean-rose host pairs were present within the selected lines. Five of the six genetic correlations estimated within the selected lines were positive (mean $=0.19, \mathrm{SE}=0.07$ ), but none was significantly different from zero (at $P<0.05$ ).

\section{Comparison of pairs of populations and estimates of genetic correlations in acceptance of host pairs}

Each host was on average equally acceptable to larvae in each pair of populations (Table 6). The Family effect was the only significant source of variation in the comparison of the Apple and Cherry populations (Table 6; Fig. 2a), suggesting significant genetic differences among families in their average host acceptance. The genetic correlation between acceptance of the apple and cherry hosts was positive but not significantly different from $0(r=0.38, P=0.07, n=23)$. Separate analysis on the Apple and Cherry populations yielded qualitatively similar results; both genetic correlations between acceptance of the apple and cherry host were 


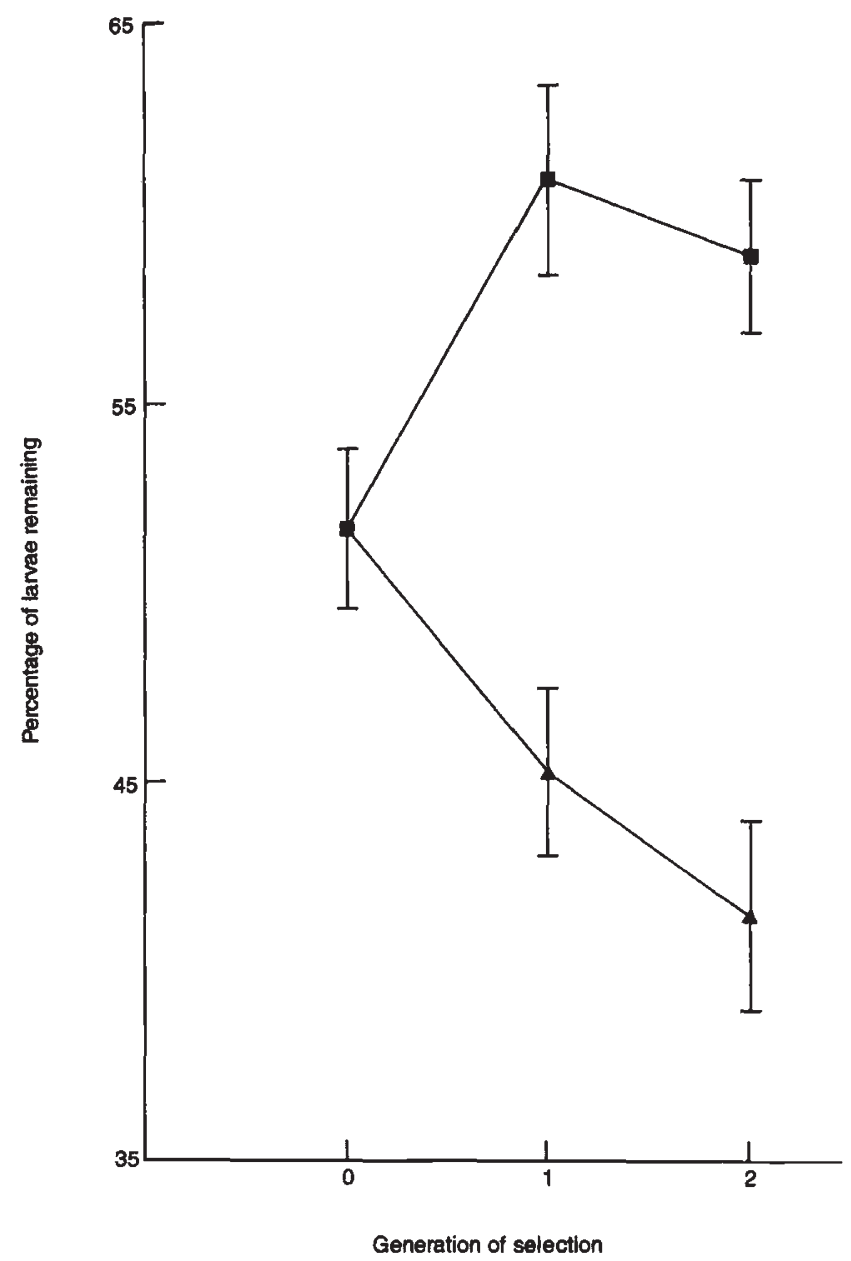

Fig. 1 Broad bean acceptance $(\% \pm S E)$ in the base population of Choristoneura rosaceana and in the first two generations of selection. Triangles, selection for lower acceptance. Squares, selection for higher acceptance. Different bioassays were used to estimate host responses in the first two and in the third generations of selection. Therefore, host responses measured after three generations of selection are presented in Table 4. positive, but not significantly different from zero $(P<0.05)$.

Comparison of the Apple and Blueberry populations revealed a significant Population effect (Table 6), indicating that individuals from the blueberry field had a higher tendency to accept the hosts than larvae from the apple orchard (Fig. 2b). The nonsignificant Population $\times$ Host effect indicates that the norms of reaction were parallel. The genetic correlations between the responses to the apple and blueberry hosts were positive but not significant in the two populations (Apple population: $r=0.30, P=0.39, n=10$; Blueberry population: $r=0.36, P=0.31, n=10$ ).

In the third comparison, the norms of reaction of the Apple and Mixed forest populations were not parallel (Table 6: Pop $\times$ Host effect; Fig. 2c). The members of each population showed a similar acceptance of mockorange $(t=-0.76$, d.f. $=16, P=0.46)$, but insects

Table 4 Host-acceptance behaviours of Choristoneura rosaceana after three generations of selection on broad bean acceptance

\begin{tabular}{cccc}
\hline Host & Line & $X$ & SE \\
\hline A & L & 46.5 & 2.7 \\
& S & 54.4 & 4.5 \\
B & L & 59.2 & 2.6 \\
& S & 74.9 & 2.2 \\
R & L & 41.9 & 2.9 \\
& S & 49.7 & 2.9 \\
\hline
\end{tabular}

The average $(X \pm \mathrm{SE})$ of the percentage of larvae that accepted a host within the families of each line is presented. Fourteen and 13 families were respectively measured in the line selected for increased $(\mathrm{S})$ or decreased $(\mathrm{L})$ acceptance of bean. The host species were apple (A), broad bean (B), and $\operatorname{rose}(\mathbf{R})$.

Table 3 ANOvAs to compare variation in Choristoneura rosaceana larval acceptance of broad bean in the first two generations of selection

\begin{tabular}{lcccrc}
\hline Source & d.f. & SS & MS & $F$ & $P$ \\
\hline First generation of selection & & & & \\
Line & 1 & 1.52 & 1.52 & 54.73 & $<0.0001$ \\
Family (Line) & 33 & 2.11 & 0.0639 & 1.92 & 0.0037 \\
$r^{2}$ & 0.37 & & & & \\
Second generation of selection & & & & \\
Line & 1 & 2.34 & 2.34 & 68.61 & $<0.0001$ \\
Family (Line) & 40 & 3.90 & 0.097 & 2.86 & $<0.0001$ \\
$r^{2}$ & 0.47 & & & & \\
\hline
\end{tabular}

$r^{2}$ measures how much variation in the dependent variable is accounted for by the model. 
from the apple orchard had much higher acceptance of apple than insects from the mixed forest $(t=3.47$, d.f. $=16, P=0.003$ ). The genetic correlations between acceptance of the pair of hosts were positive but only significantly different from 0 in the population from the mixed forest (Apple orchard: $r=0.33, P=0.38, n=9$; Mixed forest: $r=0.68, P=0.04, n=9$ ).

\section{Discussion}

The existence of genetic constraints on growth, survival, and reproduction (hereafter, performance) across phytochemically different hosts is central to many models of the evolution of diet breadth, sympatric speciation and the maintenance of genetic variation in insect herbivores (Jaenike, 1981; Diehl \& Bush, 1984; Rausher, 1984; Futuyma \& Peterson, 1985; Jaenike \& Holt, 1991; Fox, 1993; Carrière \& Roitberg, 1994; Bossart \& Scriber, 1995). In such models, genetically based trade-offs in performance on different hosts are assumed to slow the joint evolution of high performance across the potential hosts of a population (Via, 1987). Therefore, in the presence of genetic variation in host-selection behaviours, (i) preference or avoidance of some hosts may evolve at a faster rate than performance on these same hosts, thereby favouring specialization in diet, or (ii) selection may produce genetic correlations between preference and performance, thereby favouring sympatric speciation. In the present paper, we consider genetic constraints that may directly affect host-selection behaviours. Negative genetic correlations between the responses to different host species would be expected to result in trade-offs in discrimination within these host species (Singer et al., 1992; Fox \& Lalonde, 1993). If abundant, such correlations could partly explain why the majority of insect herbivores have a specialized diet (Jaenike, 1990).

Table 5 ANOVA to compare variation in host-acceptance behaviour between the selected lines of Choristoneura rosaceana after three generations of selection

\begin{tabular}{lcccc}
\hline Source & $N_{\text {d.f. }}$ & $D_{\text {d.f }}$ & $F$ & $P$ \\
\hline Host & 2 & 159 & 37.33 & 0.0001 \\
Family $($ Line $)$ & 25 & 159 & 1.83 & 0.014 \\
Line & 1 & 25.06 & 14.35 & 0.0008 \\
Host $\times$ Line & 2 & 159 & 2.36 & 0.098 \\
Host $\times$ Family $($ Line $)$ & 50 & 159 & 1.14 & 0.27 \\
$r^{2}$ & 0.57 & & & \\
\hline
\end{tabular}

$N_{\text {d.f }}$ and $D_{\text {d.f. }}$ are, respectively, the numerator and denominator degrees of freedom used in the Satterthwaite approximations of the $F$-tests (SAS Institute, 1988).

$r^{2}$ measures how much variation in the dependent variable is accounted for by the model.

Table 6 ANOvas to compare variation in larval host acceptance in three pairs of populations of the obliquebanded leafroller confined to habitats that differed in host species composition

\begin{tabular}{|c|c|c|c|c|c|c|c|c|c|c|c|c|}
\hline \multirow[b]{2}{*}{ Source } & \multicolumn{4}{|c|}{ Apple-Cherry } & \multicolumn{4}{|c|}{ Apple-Blueberry } & \multicolumn{4}{|c|}{ Apple-Mockorange } \\
\hline & $N_{\text {d.f. }}$ & $D_{\mathrm{d} . \mathrm{f}}$ & $F$ & $P$ & $N_{\text {d.f. }}$ & $D_{\text {d.f. }}$ & $F$ & $P$ & $N_{\text {d.f. }}$ & $D_{\text {d.f }}$ & $F$ & $P$ \\
\hline Pop & 1 & 6.59 & 0.002 & 0.96 & 1 & 3.16 & 14.22 & 0.030 & 1 & 1.14 & 0.53 & 0.59 \\
\hline Family (Pop) & 21 & 21 & 2.47 & 0.022 & 19 & 19.32 & 1.85 & 0.093 & 16 & 16 & 2.26 & 0.057 \\
\hline Host & 1 & 1 & 5.37 & 0.26 & 1 & 1 & 46.82 & 0.092 & 1 & 1 & 2.52 & 0.36 \\
\hline Pop $\times$ Host & 1 & 21.41 & 0.50 & 0.48 & 1 & 18.74 & 0.95 & 0.34 & 1 & 16 & 18.11 & 0.0006 \\
\hline Family $($ Pop $) \times$ Host & 21 & 178 & 1.41 & 0.12 & 18 & 114 & 1.09 & 0.37 & 16 & 144 & 1.38 & 0.16 \\
\hline$r^{2}$ & 0.37 & & & & 0.54 & & & & 0.55 & & & \\
\hline
\end{tabular}

$r^{2}$ measures how much variation in the dependent variable is accounted for by the model.

$N_{\text {d.f. }}$ and $D_{\text {d.f. }}$ are, respectively, the numerator and denominator degrees of freedom used in the Satterthwaite approximations of the $F$-tests (SAS Institute, 1988). 


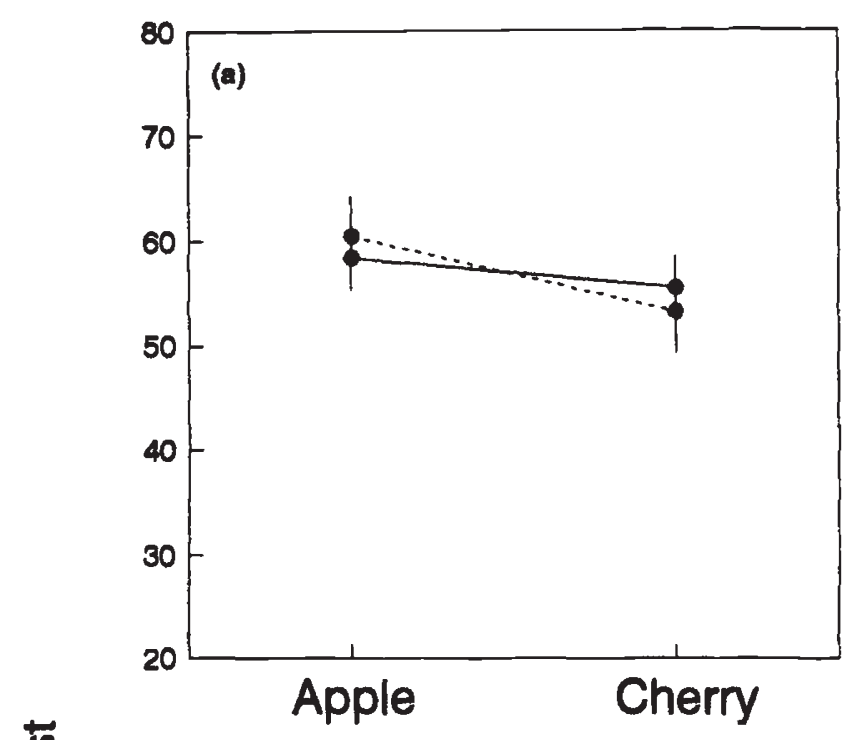

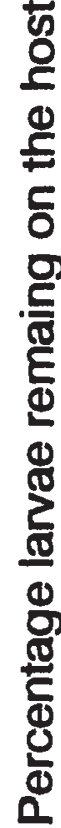
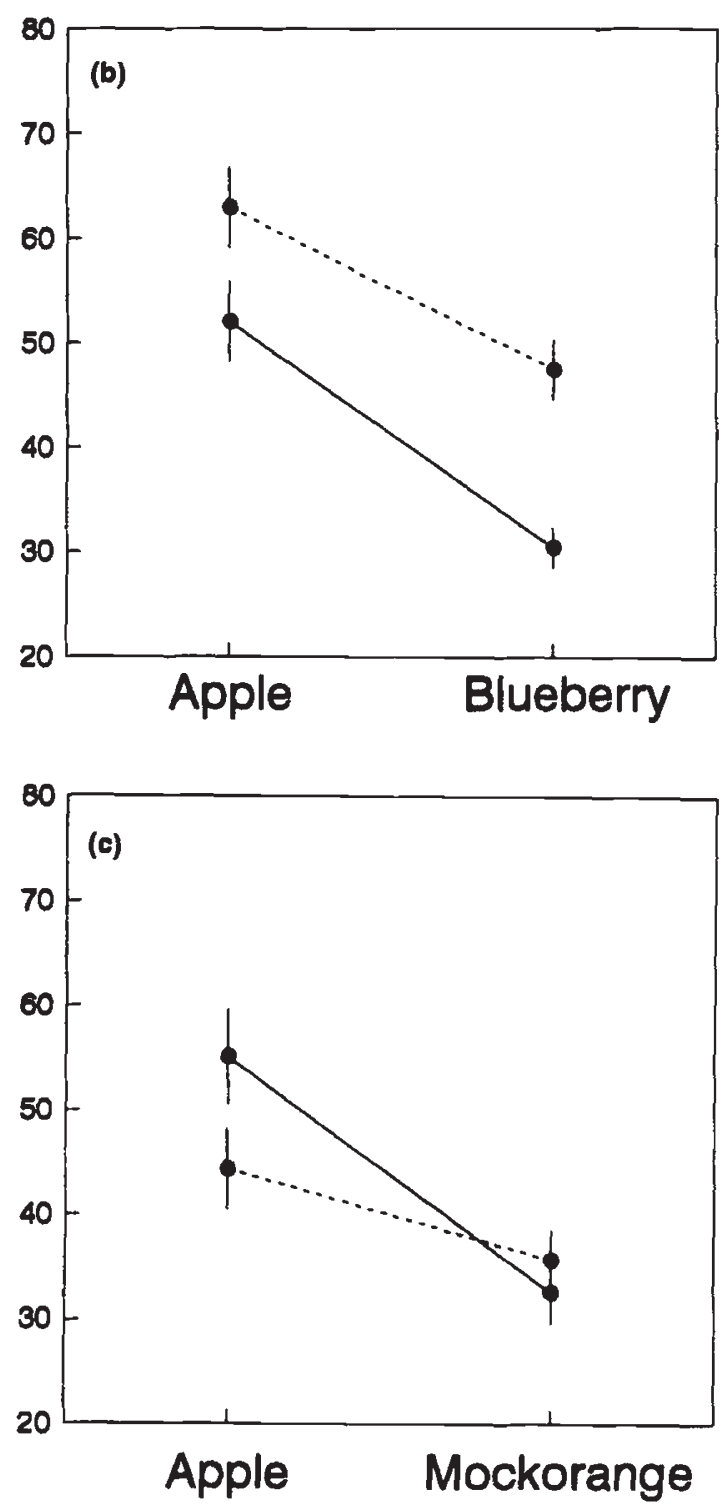

In this study, we demonstrated that genetically based variation in larval host acceptance was present within populations of $C$. rosaceana. The comparisons of pairs of populations, and the indirect responses to selection on host-acceptance behaviour, provide evidence that the genetic correlations between acceptance of different host species were either positive or not significantly different from zero. The data also suggest that the norms of reaction for host response differed in two pairs of allopatric populations, but were similar between two populations assumed to be sympatric (Fig. 2). We discuss below the implication of these findings on the evolution of diet in $C$. rosaceana and in other plant-feeding insects.

\section{Heritability of host acceptance}

Values of heritability, and the outcome of selection experiments, always depend on the environment in which the experiments are made and on the populations studied (Falconer, 1981; Via, 1990). The reliability of the bioassay to reproduce field conditions (Carrière, 1992c), the repeated significance of the family effect in different populations, and the results of the selection experiment suggest, however, that there was additive genetic variance in host-selection behaviour within field populations of $C$. rosaceana.

Heritable variation in host-selection behaviour has often been found within populations of adult herbivorous insects. Such variation is apparently common for oviposition preference (reviewed in Via, 1990; Jaenike \& Holt, 1991; Thompson \& Pellmyr, 1991). Populations of aphids can show genetically based differences in their tendency to migrate from (Lamb \& Mackay, 1979; Groeters, 1989), or move between (Bell, 1991) their hosts. Dispersal tendency (host acceptance) was shown to respond rapidly to selection in a polyphagous mite species (Fry, 1989; Li \& Margolies, 1994). Few investigations, however, have reported evidence for genetically determined differences in larval host-selection behaviour. The tendency to settle on different algal species differed genetically both within and among populations in larvae of a marine polychaete (Mackay \& Doyle, 1978). Heritable variation in food/habitat choice (Wallin, 1988; reviewed in Bell, 1991) and posi-

Fig. 2 Comparison of the average host acceptance (\% $\pm \mathrm{SE}$ ) between populations of Choristoneura rosaceana collected in different habitats. (a) Populations assumed to be sympatric and collected from apple (solid line) or cherry orchards (broken line).(b) Allopatric populations collected from an apple orchard (solid line) or a blueberry field (broken line). (c) Allopatric populations collected from an apple orchard (solid line) or a mixed forest (broken line). 
tive genetic correlation between habitat choice and development rate (Taylor \& Condra, 1983) were found in Drosophila larvae.

\section{Genetic correlations between host responses}

The differences in response to the apple and rose hosts between the selected lines suggest that positive genetic correlations between host responses were present within the selected population. In the comparisons of pairs of populations, only one of the five genetic correlations in acceptance of the host-pairs was significant, but the correlation coefficients were always positive with an average value of $0.41 \pm 0.07( \pm \mathrm{SE})$. Therefore, there is no evidence that negative genetic correlations between the responses to different host species were present in populations of $C$. rosaceana. Such a genetic architecture of host-selection behaviour implies that selection for increased acceptance of a particular host would not result in any loss of ability to accept another host, which could favour polyphagy in this leafroller.

Few studies have attempted to measure genetic correlations between the responses to hosts (Arnold, 1981; Wasserman, 1986; Courtney \& Hard, 1990), and a genetic trade-off in host response was only found in the anise swallowtail butterfly, Papilio zelicaon (Thompson, 1993). In that species, a negative genetic correlation between oviposition preference for fennel (Foeniculum vulgare) and Cymopterus terebinthinus was found in a population of ecological specialists on fennel. After escaping from cultivation, fennel was incorporated into the diet of $P$. zelicaon as a low-ranking host (Thompson, 1993). Cymopterus terebinthinus, however, is a high-ranking native host. Therefore, it can be predicted that a selective increase in preference for fennel in the monophagous population should result in a correlated decrease in preference for Cymopterus terebinthinus. A comparison of host-selection behaviour between the monophagous population and a population that exploited Cymopterus terebinthinus and another native host suggests that this prediction was realized (see Thompson, 1993, table 1). Despite the detection of such a negative genetic correlation in oviposition preference, it is remarkable that the rank-order of host preference appeared to be evolutionarily conservative across the swallowtail populations studied by Thompson (1993).

In the highly specialized Lapeyresia pomonella, however, it is clear that the evolution of increased oviposition preference for a novel host, which was initially ranked lower than the ancestral host, resulted in a change in the rank-order of host preference (Phillips \& Barnes, 1975). The L. pomonella populations were exploiting different monocultures and became special- ists on dissimilar hosts. This is in opposition to the predictions of the hierarchy threshold model (Courtney et al., 1989; Courtney \& Hard, 1990), which proposes that the rank-order of host preference in insect herbivores is evolutionarily conservative. Therefore, such a model is not allowing for the existence of strong negative genetic correlations between the tendencies to accept different hosts. The rapidity of these behavioural changes (taking place in less than 100 years), and the fact that preference for the ancestral host always declined following increased acceptance of the novel host, suggest that the divergences in behaviour were not simply because of the effect of genetic drift. Therefore, negative genetic correlations between acceptances of different hosts may play a major role in shaping diet in L. pomonella. Further studies are needed to assess the frequency of negative genetic correlations between responses to different hosts in plant-feeding insects.

\section{Comparison of norms of reaction in pairs of populations}

Optimal foraging models suggest that costs associated with host discrimination (e.g. reduction in realized fecundity, mortality due to dispersal) may be balanced by the benefit of locating highly suitable resources (Roitberg \& Mangel, 1993 and references therein). In reproductively isolated populations remaining in association with monocultures, however, the cultivated crop is virtually the only host present, and increased acceptance of the cultivated crop could be favoured. Such a modification in host-selection behaviour would be more likely to occur if a low-ranking host is colonized, since a low-ranking host could be strongly rejected initially but eventually accepted, thereby creating an opportunity for selection to decrease the length of the discrimination phase (see Wiklund, 1981; Singer, 1986).

The comparison between the Apple and Mixed forest populations (Fig. 2c) supports the hypothesis that an increase in host acceptance is favoured in monocultures. A similar phenomenon was observed in L. pomonella (Phillips \& Barnes, 1975) and in Liriomysa brassica (Tavormina, 1982). In the Blueberry population, however, larvae had a higher acceptance of the blueberry and apple hosts than individuals from the Apple population (Fig. 2b). Such a divergence in host-selection behaviour may result from two, nonexclusive factors: (i) a selective increase in blueberry acceptance in the Blueberry population may have resulted in a correlated increase in apple acceptance, and (ii) low host acceptance may have been present in the Apple population. Nevertheless, no strongly 'cross- 
ing' norms of reactions were observed in the pairs of allopatric populations. This corroborates the previous statement that the evolution of high acceptance of a specific host should favour polyphagy in C. rosaceana.

It seems reasonable to infer that local changes in host species' composition gave rise to between-population variation in larval host-selection behaviour. Interhabitat variation in other ecological factors, however, may have also influenced host-selection behaviour (Jaenike, 1990; Johnson \& Gaines, 1990). For example, across-habitat variation in mortality risk associated with larval dispersal may have favoured local changes in host acceptance. Finally, founder effects arising because the blueberry and mixed forest colonies were established from small field-collected samples may have contributed to the between population differences in host-selection behaviour.

Researchers studying the evolution of diet breadth in insect herbivores have concentrated on life history characters expressed on different hosts. The scale at which independently evolving units differ in such hostuse traits varies considerably among insect species. It ranges from individual plants (Karban, 1989), adjacent patches, fields or forest stands (Mitter et al., 1979; Schneider, 1980; Thompson, 1985; Via, 1991), to regions corresponding to allopatric sets of plant species (Scriber, 1988; Hagen, 1990). The present study suggests that local variation in host species' frequency has influenced the evolution of host-selection behaviour in $C$. rosaceana. Recent reviews of the literature (Courtney et al., 1989; Jaenike \& Holt, 1991; Carrière \& Roitberg, unpublished observations), as well as the results of this study, suggest that such an evolutionary change in host selection behaviour is generally not accompanied by behavioural specialization in plant-feeding insects.

\section{Acknowledgements}

We thank R. Preziosi, D. Roff and I. Weigensberg, and two anonymous reviewers for their comments. We would like to thank the personnel of the Summerland Agriculture Canada Research Station for their collaboration. This study was supported by a Natural Sciences and Engineering Research Council of Canada grant to B. D. Roitberg and a NSERC postgraduate scholarship to Y. Carrière.

\section{References}

ARNOLD, s. J. 1981. Behavioral variation in natural populations. 1. Phenotypic, genetic and environmental correlations among chemoreceptive responses to prey in the garter snake, Thamnophis elegans. Evolution, 35, 489-509.

BELL, w. J. 1991. The Behavioural Ecology of Finding Resources. Chapman and Hall, New York.

BOSSART, J. L. AND SCRIBER, J. M. 1995. Maintenance of ecologically significant genetic variation in the tiger swallowtail butterfly through differential selection and gene flow. Evolution, in press.

CARRIERE, Y. 1992a. Ecological Genetics of Host Exploitation in a Generalist Herbivore, the Obliquebanded Leafroller. Ph.D. Thesis, Simon Fraser University, Burnaby, BC.

CARRIERE, Y. 1992b. Host plant exploitation within a population of a generalist herbivore, Choristoneura rosaceana. Entomologia exp. appl., 65, 1-10.

CARRIERE, Y. 1992c. Larval dispersal from potential hosts within a population of a generalist herbivore, Choristoneura rosaceana. Entomologia exp. appl., 65, 11-19.

CARRIERE, Y. 1994. Evolution of phenotypic variance: nonMendelian parental influences on the phenotypic and genotypic components of the life-history traits in a generalist herbivore. Heredity, 72, 420-430.

CARRIERE, Y. AND RoITBERG, B. D. 1994. Trade-offs in performance on different hosts within a population of a generalist herbivore, Choristoneura rosaceana (Lepidoptera: Tortricidae). Entomologia exp. appl., 72, 173-180.

Courtney, S. P. 1982. Coevolution of Pierid butterflies and their cruciferous food plants. V. Habitat selection, community structure and speciation. Oecologia, 54, 101-107.

COURTNEY, S. P., CHEN, G. K. AND GARDNER, A. 1989. A general model for individual host selection. Oikos, 55, 55-65.

COURTNEY, S. P. AND HARD, J. J. 1990. Host acceptance and lifehistory traits in Drosophila busckii: tests of the hierarchythreshold model. Heredity, 64, 371-375.

DIEHL, S. R. AND BUSH, G. L. 1984. An evolutionary and applied perspective of insect biotypes. Ann. Rev. Ent., 29, 471-504.

FALCONER, D. S. 1981. Introduction to Quantitative Genetics, 2nd edn. Longman, New York.

Fox, C. w. 1993. A quantitative genetic analysis of oviposition preference and larval performance on two hosts in the bruchid beetle, Challosobruchus maculatus. Evolution, 47, 166-175.

FOX, C. W. AND LALONDE, R. G. 1993. Host confusion and the evolution of insect diet breadths. Oikos, 67, 577-581.

FRY, J. D. 1989. Evolutionary adaption in host plants in a laboratory population of the phytophagous mite Tetranychus urticae Koch. Oecologia, 81, 559-565.

FUTUYMA, D. J. 1983. Selective factors in the evolution of host choice by phytophagous insects. In: Ahmad, S. (ed.) Herbiyorous Insects, pp. 227-244. Academic Press, New York.

FUTUYMA, D. J., CORT, R. P. AND NOoDWIJK, I. 1984. Adaptation to host plants in the fall cankerworm (Alsophila pometaria) and its bearing on the evolution of host affiliation in phytophagous insects. Am. Nat., 123, 287-296.

FUTUYMA, D. J. AND PETERSON, S. C. 1985. Genetic variation in the use of resources by insects. Ann. Rev. Ent., 30, 217-238. 
GILLESPIE, D. R. 1982. Introduced and Native Leafrollers (Lepidoptera: Tortricidae) on Berry Crops in the Lower Fraser Valley, B.C. Ph.D. Thesis, Simon Fraser University, Burnaby, BC.

GROETERS, F. R. 1989. Geographic and clonal variation in the milkweed-oleander aphid, Aphis nerii (Homoptera: Aphididae), for winged morph production, life-history and morphology in relation to host plant permanence. Evol. Ecol., 3, 327-341.

HAGEN, R. H. 1990. Population structure and host use in hybridizing subspecies of Papilio glaucus (Lepidoptera: Papilionidae). Evolution, 44, 1914-1930.

HARRISON, G. D. 1987. Host-plant discrimination and evolution of feeding preference in the Colorado potato beetle Leptinotarsa decemlineata. Phys. Entomol., 12, 407-415.

JAENIKE, J. 1978. On optimal oviposition behaviour in phytophagous insects. Theor. Pop. Biol., 14, 350-356.

JAENIKE, J. 1981. Criteria for ascertaining the existence of host races. Am. Nat., 117, 830-834.

JAENIKE, J. 1990. Host specialization in phytophagous insects. Ann. Rev. Ecol. Syst., 21, 243-273.

JAENIKE, J. AND GRIMALDI, D. 1983. Genetic variation for host preference within and among populations of Drosophila tripunctata. Evolution, 37, 1023-1033.

JAENIKE, J, AND HOLT, R. D. 1991. Genetic variation for habitat preference: evidence and explanations. Am. Nat., 137, S67-S90.

JOHNSON, M. L. AND GAINES, M. S. 1990. Evolution of dispersal: theoretical models and empirical tests using birds and mammals. Ann. Rev. Ecol Syst., 21, 449-480.

KARBAN, R. 1989. Fine-scale adaptations of herbivorous thrips to individual host plants. Nature, 340, 60-61.

LAMB, R. J. AND MACKAY, P. A. 1979. Variability in migratory tendency within and among natural populations of the pea aphid, Acyrthosiphon pisum. Oecologia, 39, 289-299.

LEVINS, R. AND MACARTHUR, R. 1969. An hypothesis to explain the incidence of monophagy. Ecology, 50, 910-911.

LI, J. AND MARGOLIES, D. C. 1994. Responses to direct and indirect selection on aerial dispersal behaviour in Tetranichus urticae. Heredity, 72, 10-22.

MACKAY, T. F. C. AND DOYLE, R. W. 1978. An ecological genetic analysis of the settling behaviour of a marine polychaete: 1. Probability of settlement and gregarious behaviour. Heredity, 40, 1-12.

MITTER, C., FUTUYMA, D. J., SCHNEIDER, J. C. AND HONE, J. D. 1979. Genetic variation and host plant relations in a parthenogenetic moth. Evolution, 33, 777-790.

OTTE, D. AND JOERN, A. 1977. On feeding patterns in desert grasshoppers and the evolution of specialized diets. Proc. Acad. Sci. Philadelph, 128, 89-126.

PHILLIPS, P. A. AND BARNES, M. M. 1975. Host race formation among sympatric apple, walnut and plum populations of the codling moth, Lasperyresia pomonella. Ann. Entomol. Soc. Am., 68, 1053-1060.

PROKOPY, R. J., DIEHL, S. R. AND COLEY, S. S. 1988. Behavioral evidence for races in Rhagoletis pomonella flies. Oecologia, 76, 138-147.

RAUSHER, M. D. 1984. The evolution of habitat preference in subdivided populations. Evolution, 38, 596-608.
ROFF, D. A. 1986. The genetic basis of wing dimorphism in the sand cricket, Gryllus firmus and its relevance to the evolution of wing dimorphisms in insects. Heredity, 57, 221-231.

ROFF, D. A. 1990a. The evolution of flightlessness in insects. Ecol. Monogr., 60, 389-421.

ROFF, D. A. 1990 b. Selection for changes in the incidence of wing dimorphism in Gryllus firmus. Heredity, 65, 163-168.

ROITBERG, B. D. AND MANGEL, M. 1993. Parent-offspring conflict and life history consequences in herbivorous insects. $\mathrm{Am}$. Nat., 142, 443-456.

ROWELL-RAHIER, M. 1984. The food plant preferences of Phratoa vitellinae (Coleoptera: Chrysomelinae). Oecologia, 64, 375-380.

SAS INSTITUTE 1988. SAS/STAT User's Guide, Release 6.03 Edition. Cary, NC.

SCHNEIDER, J. C. 1980. The role of parthenogenesis and female aptery in microgeographic, ecological adaptations in the fall cankerworm, Alsophila pometaria Harris (Lepidoptera: Geometridae). Ecology, 61, 1082-1090.

SCHNEIDER, J. C. AND ROUSH, R. T. 1986. Genetic differences in oviposition preference between two populations of Heliothis virescens. In: Huettel, M. D. (ed.) Evolutionary Genetics of Invertebrate Behaviors, pp. 163-171. Plenum, New York.

SCRIBER, J. M. 1988. Tale of the tiger: beringial biogeography, binomial classification, and breakfast choices in the Papilio glaucus complex of butterflies. In: Spencer, K. (ed.) Chemical Mediation of Coevolution, pp. 241-301. Academic Press, New York.

SHOREY, H. H. AND HALE, R. C. 1965. Mass rearing of the larvae of nine noctuid species on a simple artificial medium. $J$. Econ. Entomol., 58, 522-524.

SINGER, M. C. 1986. The definition and measurement of oviposition preference in plant-feeding insects. In: Miller, T. A. and Miller, J. (eds) Insect-Plant Interactions, pp. 65-94. Springer, New York.

SINGER, M. C., THOMAS, C. D., BILLINGTON, H. L. AND PARMESAN, C. 1989. Variation among conspecific insect populations in the mechanistic basis of diet breadth. Anim. Behav., 37, 751-759.

SINGER, M. C., NG, D., VASCO, D. AND THOMAS, C. D. 1992. Rapidly evolving associations among oviposition preferences fail to constrain evolution of insect diet. Am. Nat., 139, 9-20.

SINGER, M. C. AND PARMESAN, c. 1993. Sources of variations in patterns of plant-insect association. Nature, 361, 251-253.

SOKAL, R. R. AND RoHLF, F. J. 1981. Biometry, 2nd edn. Freeman, New York.

TAVORMINA, S. J. 1982. Sympatric genetic divergence in the leaf-mining insect Liriomyza brassicae (Diptera: Agromyzidae). Evolution, 36, 523-534.

TAYLOR, C. E. AND CONDRA, c. 1983. Resource partitioning among genotypes of Drosophila pseudoobscura. Evolution, 37, 135-149.

THOMAS, C. D., NG, D., SINGER, M. C., MALLET, J. L. B., PARMESAN, C. AND BILLINGTON, H. L. 1987. Incorporation of a European weed into the diet of a North American herbivore. Evolution, 41, 892-901. 
THOMPSON, J. N. 1985. Within-patch dynamics of life-histories, populations and interactions: selection over time in small spaces. In: Pickett, S. T. A. and White, P. S. (eds) The Ecology of Natural Disturbance and Patch Dynamics, pp. 253-264. Academic Press, London.

THOMPSON, J. N. 1993. Preference hierarchies and the origin of geographic specialization in host use in swallowtail butterflies. Evolution, 47, 1585-1594.

THOMPSON, J. N. AND PELlMYR, o. 1991. Evolution of oviposition behavior and host preference in Lepidoptera. Ann. Rev. Ent., 36, 65-89.

VIA, s. 1987. Genetic constraints on the evolution of phenotypic plasticity. In: Loeschcke, V. (ed.) Genetic Constraints on Adaptive Evolution, pp. 47-73. Springer, New York.

VIA, S. 1990. Ecological genetics of herbivorous insects: the experimental study of evolution in natural and agricultural systems. Ann. Rev. Ent., 35, 421-446.
VIA, S. 1991. The genetic structure of host plant adaption in a spatial patchwork: demographic variability among reciprocally transplanted pea aphid clones. Evolution, 45, 827-852.

WARD, S. A. 1987 . Optimal habitat selection in time-limited dispersers. Am. Nat., 129, 568-579.

WALLIN, A. 1988. The genetics of foraging behaviour: artificial selection for food choice in larvae of the fruit fly, Drosophila melanogaster. Anim. Behav., 36, 106-114.

WASSERMAN, S. S. 1986. Genetic variation in adaptation to foodplants among populations of the southern cowpea weevil, Callosobruchus maculatus: evolution of oviposition preference. Entomologia exp. appl., 42, 201-212.

WiKLUND, c. 1981. Generalist vs. specialist oviposition behaviour in Papilio machaon (Lepidoptera) and functional aspects on the hierarchy of oviposition preferences. Oikos, 36, 163-170. 